\title{
Palestras sobre a psicopatologia e a sua importância para a psicologia normal*
}

Gustav Störring

\section{Primeira palestra}

Definição da psicologia e da psicopatologia. Características gerais da importância da psicopatologia para a psicologia. Importância da anatomia e da fisiologia para os exames psicológicos.

Paralelismo psico-físico

Levando em consideração que essa palestra trata da importância da psicopatologia para a psicologia normal, seria útil definir, em primeiro lugar, o que entendo por psicologia, em seguida explicar o que se entende por psicopatologia e depois caracterizar, de maneira geral, a importância da psicopatologia para a psicologia.

O objeto da psicologia foi definido de várias formas. Foi dito: a psicologia é a ciência da alma. Trata-se de uma definição antiga. Ela se tornou inadequada por colocar uma afirmação metafísica à frente de uma ciência empírica. Ela define a existência da alma como sendo

* Publicado originalmente em 1900, em Leipzig, pela Editora Wilhelm Engelmann. Tradução para o português de Lumina Traduções. 
um substrato, um portador dos processos de consciência. Porém, a existência de tal substrato para os processos de consciência é amplamente contestada. Por isso, torna-se mais conveniente definir a psicologia como a ciência dos processos de consciência. Todos nós sabemos o que se entende por processos de consciência. São nossos pensamentos, sentimentos, paixões, desejos, ânsias e atos volitivos — falamos normalmente de forma resumida de ideias, sentimentos e atos volitivos. Entretanto, deixaremos em aberto a questão se esses são os fenômenos psíquicos básicos. A consciência não é um fator separado, isolado desses processos, mas uma característica que faz parte deles, ou seja, uma das suas condições elementares, de modo que não conseguimos defini-la no sentido estrito da palavra. Podemos apenas apontar para ela.

Essa definição da psicologia tem sido contestada pelo argumento de que ela não examina apenas os processos de consciência, mas também determinados processos inconscientes, os quais são costumeiramente chamados de ideias inconscientes. Percebemos com facilidade que a escolha do termo foi infeliz, tendo em vista que as ideias definem um determinado tipo de processo de consciência. Porém, tal refutação terminológica não nos exime de verificar a questão.

O que entendemos por ideias inconscientes? Os defensores da existência de ideias inconscientes argumentam que na cadeia causal que liga os processos de consciência se encontram elos individuais que não são conscientes. Alguns autores definem esses elos intermediários inconscientes como fatores psicológicos, enquanto outros os consideram fatores puramente fisiológicos. A questão da existência de tais processos será elucidada mais tarde, no decorrer de nossa investigação. Por enquanto, aceitaremos a realidade dessas operações. Segundo a definição acima, o seu tratamento deve ser excluído do campo da psicologia. Porém, ao examinar melhor a relação entre essas ideias chamadas de inconscientes e os processos de consciência, percebemos que isso não se aplica. Tendo em vista que a psicologia trata dos processos de consciência, ela procura analisar e definir as leis de suas relações causais. Agora, por hipótese, os processos de consciência não são uma cadeia fechada de causa e efeito, pois há nela elos intermediários inconscientes. Portanto, se objetivamos estudar os processos de consciência, se queremos desvendar suas relações causais, somos obrigados a levar em consideração os processos inconscientes como meio para atingir essa finalidade. Porém, nesse ponto de vista, as chamadas ideias inconscientes não são objeto de estudo da psicologia, como é o caso para os processos de consciência. Mas isso não deveria causar nenhum problema. 


\section{CLÁSSICOS DA PSICOPATOLOGIA}

A psicologia é então a ciência dos processos de consciência. A sua tarefa consiste em analisar esses processos, ou seja: ela deve realizar um levantamento dos seus elementos e, ao mesmo tempo, definir as leis pelas quais esses elementos se ligam ou se fundem e, por outro lado, se encadeiam uns aos outros.

Definiremos agora o termo de psicopatologia. Entende-se por ele a ciência dos processos mórbidos da consciência. Fazemos a diferença entre a psicopatologia geral e a específica. Uma demonstração da diferença através de um exemplo nos ajudará a reconhecer facilmente o tipo apropriado de psicopatologia para a nossa finalidade, tendo em vista que o nosso objetivo é falar sobre a importância da psicopatologia para a psicologia.

Os distúrbios melancólicos são encontrados numa variedade de distúrbios mentais. Por um lado, eles podem se manifestar como doença independente, a melancolia. Por outro lado, podem se manifestar no decorrer da paralisia progressiva, da encefalomalacia progressiva e ocorrer também nos maníacos crônicos e, finalmente, na chamada loucura circular, uma doença mental na qual os estados de excitação maníaca alternam periodicamente com os de melancolia.

Os distúrbios melancólicos são, portanto, apenas um sintoma de uma doença mental. A psicopatologia trata então, na sua parte geral, dos sintomas das doenças mentais. Ela descreve os sintomas e verifica seus efeitos sobre a vida interior. $\mathrm{Na}$ psicopatologia geral, as doenças mentais são tratadas puramente do ponto de vista psicológico. Ela é, portanto, geralmente dividida em teoria das anomalias da cognição, das anomalias do afeto e das anomalias da volição.

Em contrapartida, a psicopatologia especial desenvolve os quadros clínicos das doenças. Ela não tem nenhum interesse psicológico, apenas um interesse prognóstico-terapêutico puramente medicinal. Ela sintetiza os quadros clínicos com base nos sintomas individuais que ocorrem durante o processo das doenças. Os livros de psiquiatria mais recentes tratam em primeiro lugar da psicopatologia geral e, em seguida, da especial, porque o tratamento psicológico dos sintomas é necessário para a compreensão dos quadros clínicos.

Assim, ao definir a importância da psicopatologia para a psicologia, torna-se claro que tratamos do significado da psicopatologia geral para a psicologia.

A psicopatologia e a psicologia se encontram numa relação recíproca. A psicologia possui um significado para a psicopatologia e a psicopatologia 
possui um significado para a psicologia. Então, é essa última relação que nos interessa e seria vantajoso estabelecer uma caracterização geral da importância que a psicopatologia tem para a psicologia. Devido a essa importância, adotei o termo "método psicopatológico" na psicologia. Para colocá-lo em perspectiva, seguem algumas palavras sobre os métodos psicológicos em geral.

A psicologia metafísica era baseada, como o próprio nome sugere, em concepções metafísicas gerais que ela impunha à vida psíquica e se desenvolvia mais através da especulação do que da simples observação. Além disso, seu escopo de interesse era muito estreito. Apenas o que podia ser posto em relação para definir a natureza da alma se tornava objeto de pesquisa científica.

Hoje, essa linha psicológica está obsoleta e foi superada. A psicologia metafísica foi substituída pela psicologia empírica da auto-observação. Ela é baseada nos fatos isolados da vida psíquica, procura analisá-los e encontrar regularidades nas suas combinações e sucessões. O método utilizado é o da auto-observação.

Encontramos uma crítica interessante desse método em Auguste

314 Comte: "É obviamente impossível observar alguns fenômenos intelectuais durante sua decorrência. $\mathrm{O}$ indivíduo pensante não consegue se dividir em dois, um dos quais pensa, enquanto o outro o observa. $\mathrm{O}$ órgão que observa e aquele que é observado são idênticos, nesse caso. Assim, como poderia ocorrer a observação? Portanto, esse pressuposto método psicológico está, desde o princípio, radicalmente obsoleto. E somos também imediatamente confrontados com as maneiras bastante contraditórias do processo! Por um lado, somos instruídos a nos isolar de toda percepção externa e especialmente de suspender qualquer trabalho intelectual, pois o que se tornaria a observação interna se estivéssemos ocupados com o mais simples problema de matemática? Por outro lado, quando essas medidas finalmente nos levam ao estado mais perfeito do sono intelectual, somos instruídos a observar as atividades da mente, sendo que nada mais está ocorrendo nela. Tenho certeza de que os nossos descendentes vão levar isso para o palco, para a sua diversão." (Citado por Brentano, Psychologie v. emp. Stdpkt. [A psicologia do ponto de vista empírico]). Friedrich Albert Lange fez observações semelhantes.

Aqui, a possibilidade de observar fenômenos psíquicos é negada porque tal observação pressupõe uma impossível autoduplicação. Porém, não podemos concordar com isso. A auto-observação não pressupõe nenhuma 


\section{CLÁSSICOS DA PSICOPATOLOGIA}

autoduplicação. A essência da auto-observação pode ser formulada da seguinte maneira: Eu me observo. Assim, a mesma variável parece ser sujeito e objeto da observação ao mesmo tempo. Porém, o Eu não é, como veremos, uma variável simples, mas uma variável composta. $\mathrm{O}$ fato é simplesmente que durante a auto-observação, a atenção é dirigida para um processo psíquico em andamento. Teríamos, então, dois processos psíquicos ocorrendo ao mesmo tempo. Isso não é uma contradição em si. Porém, se direcionamos a nossa atenção para os fenômenos psíquicos em andamento, podemos modificá-los. Sabemos que o afeto diminui na medida em que a atenção se concentra na sua manifestação. Adotou-se, na prática, a seguinte hipótese de trabalho: apesar de ser impossível observar um fenômeno psíquico durante a sua manifestação, temos, no entanto, consciência dele enquanto ocorre e podemos, imediatamente após o seu término, torná-lo objeto da nossa pesquisa. $\mathrm{O}$ afeto não poderá ser observado enquanto ele estiver ocorrendo, mas o afeto reproduzido não será mais influenciado pela observação. Porém, é deplorável ter que renunciar à possibilidade de um registro nítido e claro de um fenômeno psíquico que gostaríamos de observar através da atenção direcionada e que não ocorre com tanta frequência na alternância dos processos psíquicos. Porém, afirmo que não precisamos desistir totalmente do uso da atenção para essa finalidade. Depende apenas da maneira como ela for direcionada. Se a atenção for concentrada na direção na qual ela funciona, no início da manifestação de determinados fenômenos, seus processos não serão afetados, mas intensificados. Ou seja, a intensidade de um determinado afeto certamente não será diminuída se direcionamos maior atenção para o objeto cuja ideia o provocou. Porém, na maioria dos casos, essa intensificação da percepção do fenômeno psíquico chegará tarde. Além disso, o que prejudica ainda mais esse método é que dependemos do acaso para captar o ponto inicial dos fenômenos apropriados. Por fim, será difícil eliminar completamente a influência de opiniões preconcebidas sobre a interpretação dos fatos.

\section{A pesquisa psicológica será mais bem-sucedida através do auxílio do experimento}

Quando os processos psíquicos a serem pesquisados são gerados experimentalmente por uma ação física do pesquisador sobre um observador surge inicialmente a possibilidade, para o observador, de concentrar sua 
atenção no estímulo inicial. Nessa geração intencional dos fenômenos psíquicos torna-se possível comunicar o momento inicial do estímulo ao observador através de um intervalo previamente definido cujo início é indicado por um sinal. Assim, as condições fisiológicas da percepção são mais bem preparadas, pois os sentidos se adaptam então ao estímulo. Do lado psíquico, isso resulta num foco mais estreito da consciência, o que intensifica mais a manifestação do que quando o fenômeno ocorre de maneira aleatória.

A programação da atenção pode então resultar na preparação fisiológica e psicológica para o estímulo que causa a manifestação.

Foi contestado que, aqui, a atenção desempenha um papel semelhante ao que ela possui na auto-observação subjetiva. No nosso caso, como não reconhecemos de maneira tão geral os efeitos nocivos da atenção também sobre a auto-observação subjetiva, é importante saber para que aspecto a atenção foi direcionada. Aqui, ela é direcionada para o estímulo externo. Esse direcionamento para o estímulo externo só pode favorecer a manifestação nítida e clara dos fenômenos psíquicos, o que é o resultado de condições fisiológicas e psíquicas mais favoráveis, pois ela assume esse mesmo direcionamento da atenção durante a ocorrência normal desses fenômenos.

A reprodução experimental desses processos psíquicos resulta numa vantagem adicional, ou seja: ela permite repetir o processo psíquico quantas vezes for necessário.

No entanto, a repetição que envolve variáveis psíquicas bastante complexas deve ser configurada de tal modo que as melhores condições possíveis sejam obtidas para o levantamento nítido e claro dessas variáveis.

A reprodução experimental de fenômenos psíquicos também permite excluir inteiramente a influência de preconceitos sobre a concepção dos fatos psíquicos. Isso se torna possível porque, aqui, o pesquisador e o observador podem ser pessoas distintas e o observador não necessita conhecer as intenções do experimentador.

As vantagens acima mencionadas para a auto-observação durante o experimento beneficiam a nítida e clara determinação dos fenômenos psíquicos a serem examinados. Tal manifestação nítida e clara do processo psíquico é, porém, a condição básica para a sua análise e para a determinação das relações de dependência.

Distinguimos entre análise subjetiva e análise objetiva das variáveis psíquicas. A análise subjetiva é realizada de maneira introspectiva, após a observação clara e nítida do processo psíquico estudado. A análise objetiva ocorre de modo experimental. Durante o experimento, temos a possibilidade 


\section{CLÁSSICOS DA PSICOPATOLOGIA}

de variar livremente o estímulo físico que desencadeia o fenômeno psíquico, o que, consequentemente, o altera.

Quanto ao afeto e aos atos volitivos, dispomos de mais uma ferramenta para a realização de uma análise objetiva. Os processos afetivos e volitivos possuem determinados efeitos físicos que os acompanham ou que deles resultam, respectivamente. Os sentimentos são acompanhados por determinadas mudanças na respiração, na pulsação, na irrigação sanguínea das partes individuais do corpo, na tensão muscular. Os atos volitivos externos são caracterizados por determinados movimentos físicos. Podemos então examinar esses efeitos físicos por meio de exames experimentais e tentar tirar conclusões a respeito dos processos psíquicos que os acompanham ou precedem.

Finalmente, algumas palavras sobre o levantamento das relações de dependência do processo psíquico a ser examinado. Devemos distinguir entre relações de dependência de processos físicos e relações de dependência de processos psíquicos. A possibilidade de efetuar essa distinção através do experimento não requer nenhuma discussão mais aprofundada. O levantamento das dependências psíquicas é particularmente favorecido pelo experimento, pois ele permite obter uma quantidade qualquer de um determinado tipo de vivências de diferentes qualidades. Refiro-me aqui a experimentos que visam à associação e o reconhecimento.

Nessa área, a possibilidade do experimento depende do fato de um determinado processo psíquico estar numa relação de dependência com um processo físico, de tal modo que aquele possa ser desencadeado por este. No entanto, não apenas os atos de sensação e imaginação, mas também os de sentimento de vontade encontram-se numa relação de dependência com os processos físicos. Obviamente, a dificuldade de desencadear um processo psíquico por meio de um impacto físico aumenta na medida em que esse processo psíquico se torna mais complexo. Aqui surgem então algumas dificuldades para o experimento.

É nessa altura que necessitamos do apoio do estudo da patologia da vida psíquica, pois nos casos patológicos, a natureza realiza os experimentos no nosso lugar e estes visam com muito mais frequência os fenômenos psíquicos complexos do que o simples, porque os complexos ocorrem com mais frequência. A fim de definir o funcionamento normal dos órgãos do corpo, a medicina também não se restringe à simples observação e ao experimento. A patologia dos órgãos torna-se uma ferramenta essencial para a definição do funcionamento fisiológico normal dos órgãos do corpo. 
Portanto, nada mais natural do que completar a simples observação que visa à definição das funções psíquicas normais - não apenas com o nosso experimento, mas também com o da natureza, ou seja, com os casos patológicos.

Entre os fatos da vida psíquica patológica, os casos mais valiosos são aqueles nos quais apenas um componente da vida psíquica sofreu uma alteração primária. Isso corresponde a uma perfeita analogia de um dos nossos experimentos. A alteração de uma única componente da vida psíquica permite identificar:

1. Os efeitos que esse componente produz, junto com outras causas (levando em consideração que para desencadear um efeito, várias causas são sempre necessárias); e

2. A contribuição desse componente sobre os possíveis efeitos e seus desencadeamentos.

Nos casos patológicos, a alteração de um componente permite com frequência reconhecer mais facilmente aquilo que permanece indistinto na vida psíquica normal. Nesse caso, a intensidade do componente alterado é aumentada.

Um caso especial de alteração de um componente é dado quando um componente falhar. Esses casos são particularmente importantes para a análise. Nisso, a comparação com os respectivos fenômenos normais frequentemente mostra que esse componente é parte do respectivo complexo da vida psíquica normal.

O que mais se assemelha à alteração primária de apenas um componente da vida psíquica, em termos de valor para a psicologia normal, é a alteração de um número limitado de componentes da vida psíquica. Nisso, a diferente constelação desses componentes nos diversos casos permite chegar a uma conclusão sobre o efeito dos componentes individuais.

Outra vantagem dos fenômenos patológicos para a psicologia normal é que eles representam possibilidades de verificação para as teorias psicológicas, pois uma teoria psicológica se torna recomendável na medida em que consegue explicar os fenômenos patológicos com mais facilidade. Portanto, os fatos patológicos são uma referência fundamental para a validade das teorias psicológicas. Se levarmos em consideração que há, frequentemente, nas diferentes áreas de pesquisa várias teorias que parecem ter uma probabilidade semelhante, então podemos assim avaliar a validade dos critérios de probabilidade dessas teorias, a validade das possibilidades de verificação nessas áreas. 


\section{CLÁSSICOS DA PSICOPATOLOGIA}

A importância da psicopatologia para a psicologia normal se encontra finalmente também no fato de que o estudo de casos patológicos determina a formulação de questões que se referem a novos problemas. Há muitos casos patológicos que não conseguem explicar os fatos da psicologia, mas que, pelo contrário, precisariam ser explicados através da própria psicologia. Porém, mesmo esses casos possuem um valor para a psicologia. A capacidade de formular questões fecundas encontra-se entre as condições essenciais para $\mathrm{o}$ progresso da ciência. Obtemos uma grande quantidade dessas questões através da patologia psíquica.

Apesar da importância fundamental da psicopatologia para a psicologia, os fatos patológicos foram pouco explorados pela psicologia até hoje. Isso se deve ao fato externo de que, até agora, os patologistas não foram psicólogos o suficiente e que os psicólogos não foram patologistas o bastante.

Tendo em vista que a natureza realiza aqui o mesmo que é conseguido na psicologia normal através do experimento, a observação de tais fenômenos possui a validade de um experimento realizado pela psicologia normal. Portanto, esses experimentos da natureza devem ser estritamente separados dos experimentos realizados em doentes mentais.

Depois de ter definido ambos, a psicologia e a psicopatologia, e de ter justificado as características da psicopatologia que são importantes para a psicologia, gostaria de definir como a anatomia e a fisiologia se relacionam com o nosso objeto de estudo.

Em primeiro lugar, gostaria de definir rapidamente a relação dos processos psíquicos com os fisiológicos, até onde eles possam ser levados em consideração para os nossos objetivos.

$\mathrm{Na}$ nossa época, em que a psicologia é baseada no modo experimental exato, é geralmente aceito o princípio de que todos os processos psíquicos são acompanhados por processos físicos (fisiológicos) e que ambos se encontram numa relação funcional recíproca que não permite que uma alteração de uma das variáveis ocorra sem a alteração correspondente da outra variável.

De modo semelhante, a pesquisa psicológica é agora baseada no pressuposto de que os processos fisiológicos correlacionados aos processos psicológicos formam uma cadeia causal fechada em si. Podemos defender esse segundo princípio junto com Wundt, ${ }^{1}$ argumentando que uma das

\footnotetext{
${ }^{1}$ Os números remetem à Bibliografia que se encontra no final do livro.
} 
primeiras regras da lógica científica afirma "que apenas fatos que são semelhantes entre si podem fazer parte de uma correlação compreensível de condições e consequências, pois é apenas nesse caso que eles podem ser medidos por meio de um sistema de medição geral e classificados de acordo com leis compartilhadas".1 1. c. p. 6 e 7.

Precisaremos agora tratar da importância da visão anatômico-fisiológica para a nossa área.

Há psicopatologistas que gostariam de resolver os enigmas da vida psíquica pela abordagem anátomo-fisiológica. Porém, é óbvio que mesmo a compreensão completa do nexo de causalidade dos processos fisiológicos do córtex cerebral, os quais ocorrem paralelamente aos processos psíquicos, não consegue revelar a natureza dos processos psíquicos correspondentes.

Suponhamos que conhecemos todas as vias anatômicas e todos os centros anatômicos utilizados por um determinado processo de excitação que ocorre durante um processo psíquico. Ainda assim, não saberíamos o que acontece nessas vias, não conheceríamos as diferentes prioridades fisiológicas que ocorrem, muito menos os processos psíquicos que correspondem a esses processos fisiológicos. E mesmo se conhecêssemos esses processos fisiológicos, em sua natureza e nas suas relações, não conheceríamos os processos psíquicos.

Outros autores, que também superestimam a abordagem anatômico-fisiológica, não desprezam completamente o fator psíquico, mas acreditam não ser legítimo aceitar uma análise inteiramente transparente de um processo psíquico, nem mesmo quando, num determinado caso, não houver nada do lado fisiológico do que meras construções vagas. É então dada a preferência às construções hipotéticas do lado fisiológico como explicação científica (em detrimento das hipóteses), com base em fatos claramente determináveis pelas observações ou experimentos, como se o que se consta claramente do lado psíquico fosse menos confiável do que o que se encontra, ou até mesmo se pressupõe, do lado fisiológico. Esse ponto de vista se contrapõe ao método científico geral.

$\mathrm{Na}$ maioria dos casos, a abordagem psicológica é mais produtiva do que a abordagem anátomo-fisiológica.

Possuímos então, por exemplo, devido à abordagem psicológica, o conhecimento das leis essenciais que definem a sucessão das nossas ideias, enquanto a natureza dos processos fisiológicos correspondentes ainda está uma incógnita total. 


\section{CLÁSSICOS DA PSICOPATOLOGIA}

Porém, seria um erro se restringir unicamente à abordagem psicológica. Por um lado, os experimentos psicológicos exigem os fatores fisiológicos, pois estes fazem parte do conjunto das causas, por exemplo, quando utilizamos um estímulo físico para criar uma sensação. Por outro lado, há casos em que a análise psíquica é apenas obtida por meio da análise do quadro fisiológico-anatômico. Isso se torna evidente, por exemplo, nos casos de semiconsciência patológica, em que a mera análise psicológica não basta para detectar se esse estado de consciência alterada é causado por uma alteração das percepções orgânicas. Porém, a utilização da abordagem anátomo-fisiológica ajuda a detectar as relações de dependência desses estados, como veremos mais adiante. Aqui, o quadro psíquico não pode ser analisado pelo lado psíquico de maneira confiável, pois as percepções orgânicas, cujas mudanças devem ser levadas em consideração, não estão no foco da consciência.

Devemos também recorrer à abordagem fisiológica quando, no decorrer de um processo fisiológico-psíquico, um ou vários elos permanecem ocultos ou não podem ser detectados. Os princípios estabelecidos acima, que regem a relação geral entre os processos psíquicos e fisiológicos, justificam completar o exame psicológico dessa maneira. Voltaremos a esse ponto mais tarde, com muita frequência.

Portanto, decido a questão da preferência entre a abordagem fisiológica ou psicológica para o estudo dos processos psicológicos da seguinte maneira: a análise dos processos psíquicos deve acontecer principalmente através da abordagem psíquica, mas a análise deve frequentemente ser apoiada por fatores fisiológicos, sem os quais determinados casos não poderiam nem ser

GuSTAV StöRRING (1860-1946)

Professor associado de Filosofia na Universidade de Leipzig.

(cc) BY-NC

This is an open-access article, which permits unrestricted use, distribution, and reproduction in any medium for non-commercial purposes provided the original authors and sources are credited. 